\title{
PROTECTION OF THE GRAFT WITH CONDOM IN KERATOPLASTY*
}

\author{
BY \\ A. MIKLÓS AND L. MASOVSZKY \\ Szombathely, Hungary
}

IN the course of time several more or less successful procedures have been recommended to protect corneal grafts. The fact, however, that ophthalmic surgeons with many patients recommend different methods proves that a method of choice still does not exist. The ever-increasing number of keratoplasty operations shows, however, that the problem has passed the stage of experimentation, and that the operation may now be regarded as a routine procedure. A simple and effective method of protecting the graft has thus become an important topic.

Vannas (1939) recommended a small oblong rubber membrane for the protection of the transplant. He fixed the covering rubber near the limbus below and above with three to five episcleral sutures. He emphasizes that condom is the best covering material because of its thinness, elasticity, and transparency. This simple and easy method has not been universally adopted, chiefly because the extensibility of the oblong rubber membrane has not proved entirely satisfactory.

We have been performing the great majority of our keratoplasties for more than 10 years by the method recommended by Vannas, and have had ample opportunity to discover all its difficulties. The original method of fixation is not quite satisfactory because of the looseness of the longer sides of the oblong membrane, but the general idea is excellent and with slight modifications this may be regarded as the safest means of indirect protection. The covering should be made circular, slightly larger than the host cornea, and fixed in several places near the limbus to the episclera.

Harms (1948) modified the method of Vannas in much the same way, but his article found no response in the non-German literature, partly because it was very brief and partly because he solved only part of the problem. Even with his modification some technical difficulties remained, and the fixation of the rubber membrane was a rather fiddling and difficult job.

The following procedure is an improvement on the Vannas-Harms condom method. A rubber membrane, usually with a radius $2 \mathrm{~mm}$. greater than that of the host cornea, is cut with a suitably sized punch of the type used for punching leather. The condom membrane is put on a soft wooden

* Based on a paper read at a meeting of the Trans-Tisza Ophthalmological Society, Debrecen, on April 30, 1956, and at a meeting of the Hungarian Ophthalmological Society on May 15, 1956.

Received for publication July 22, 1957. 
plate, and $1.5 \mathrm{~mm}$. inside its margin fine sewing needles are used to insert $6 / 0$ black silk at $12,2,4,6,8$, and 10 o'clock. To prevent the folding of the condom membrane the inserted threads are tied over fine pincers. The covering rubber membrane is then perforated either with a fine platinum cautery or with an Elliott trephine $1 \mathrm{~mm}$. in diameter. The loop of the cautery is made white hot and the size of the holes is regulated by the perforation time. These perforations are made in a circle $3 \mathrm{~mm}$. inside the margin of the membrane, their number depending on the diameter of the protecting membrane. Besides the marginal perforations a hole is also made in the centre.

The condom membrane is sterilized for $24 \mathrm{hrs}$ in a penicillin bath $(10,000$ I.U./ml.) or for 3 minutes in boiling water. After sterilization the rubber membrane is placed in sterile gauze, and the dried threads are arranged ready for use.

After exposure with a Pretori speculum, bridle sutures are inserted into the superior and inferior rectus muscles to fix the globe and make the insertion easier.

The rubber membrane prepared beforehand is then centred on the host cornea, the sutures lying at 12, 2, 4, 6, 8, and 10 o'clock (Fig. 1).

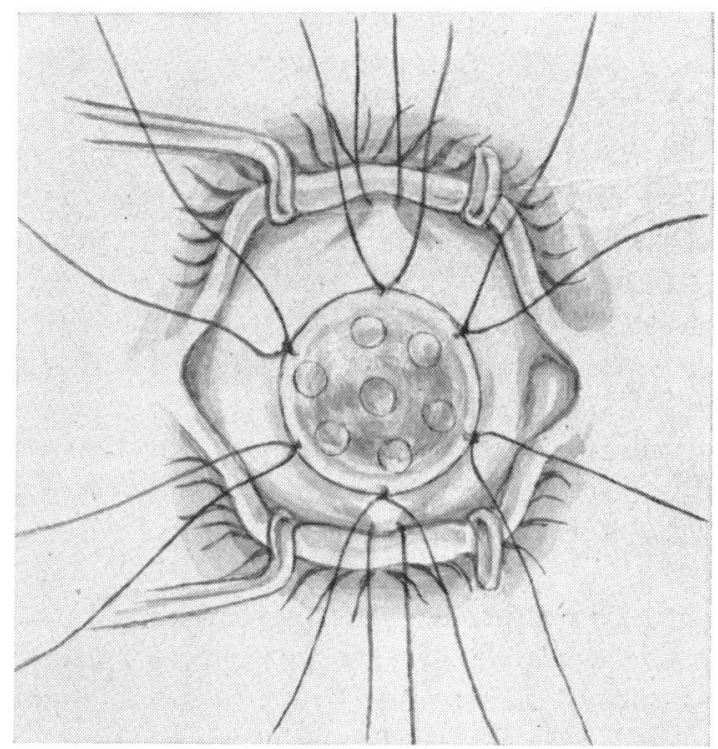

Fig. 1.-The condom membrane prepared beforehand is placed on the host cornea. The threads are at 12, 2, 4, 6,8 , and 10 o'clock, and the central hole is at the centre of the host cornea.

The thread at 6 o'clock is inserted $2 \mathrm{~mm}$. below the limbus into the episclera, knotted immediately, cut short. The episcleral insertion of the needle can be facilitated by first making small superficial incisions into the 
sclera with a knife or a keratome. The threads at 4 and 8 o'clock are then inserted in the same way (Fig. 2).

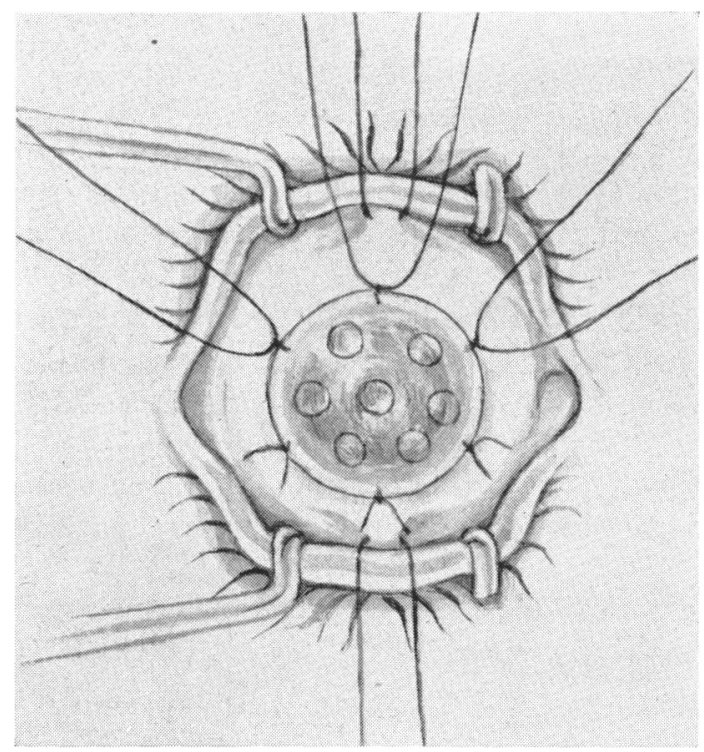

Fig. 2.-Position after the three lower episcleral threads have been inserted, tied, and cut.

When the lower threads have been tied, the rubber membrane does not slide about any more and no further difficulty is encountered in fixing it.

The surgeon inserts the thread at 12 o'clock into the episclera, the assistant helping him by stretching the rubber membrane with fine forceps. This thread is not tied, and the assistant holds it together with the upper bridle suture which makes the other insertions easier. The insertions at 10 and 12 o'clock are made like the previous one and are also left untied. In anchoring the membrane care must be taken that the rubber is properly stretched; the protecting membrane should lie smoothly without folding on the host cornea, as the fixation effect required can be achieved only in this way.

When all the sutures are in place, the membrane is turned down and the threads are held aside, while the keratoplasty is performed (Fig. 3, opposite).

After the operation the covering membrane is put in its place and the three last sutures are tied (Fig. 4, opposite).

The protecting membrane is usually removed on the 8th day. In our experience the sutures of the rubber membrane will not tear out if it is properly stretched and the tension is satisfactory.

\section{Summary}

Condom, as recommended by Vannas $(1939,1950)$, is the best material 
for the indirect protection of a corneal graft. His method was modified by

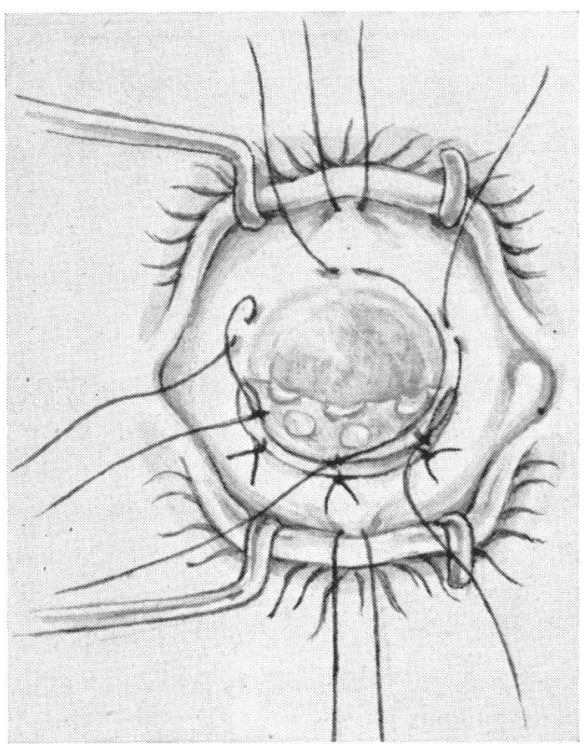

Fig. 3.-The threads at 10, 12, and 2 o'clock have been inserted and the rubber membrane has been turned back.



Fig. 4.-Position of the rubber membrane after grafting has been performed and the sutures have been tied.

Harms $(1948,1956)$, who cut a circular rubber membrane and sutured it to the episclera at six points on the limbus.

This method is a further development of the Vannas-Harms condom method, which simplifies the performance of the operation, and holds the transplant perfectly in place.

\section{REFERENCES}

Harms, H. (1948). Klin. Mbl. Augenheilk., 113, 59.

(1956). Keratoplasty Symposium, Greifswald, July, 1956.

Vannas, M. (1939). v. Graefes Arch. Ophthal., 140, 709.

(1950). Amer. J. Ophthal., 33, March, pt. 2, p. 70. 